\title{
Arbor
}

\section{La implantación de las formas artísticas romanas en Colonia Patricia Corduba, capital de la Bética}

José Antonio. Garriguet Mata

Arbor CLXVI, 654 (Junio 2000), 157-174 pp.

\section{Introducción}

Los datos disponibles a partir de la documentación literaria no permiten precisar cuál fue la fecha exacta en la que se llevó a cabo la fundación de la Córdoba romana, si bien este hecho debió acontecer muy probablemente en el segundo cuarto del siglo II a.C ${ }^{1}$. Pero lo que sí expresan con total claridad los textos antiguos stós concretamente, el geógrafo griego Estrabón, es que Corduba fue habitada desde sus inicios por «romanos e indígenas selectos» ${ }^{2}$. Con independencia de las implicaciones que la conocida cita de Estrabón ha tenido para defender tradicionalmente la idea de un núcleo de población doble o dípolis, cuya existencia ha sido confirmada por la arqueología ${ }^{3}$, esta dualidad de gentes - que a principios de la etapa imperial todavía permanecía viva en la memoria de los habitantes de la ciudad, como testimonian los nombres de dos barrios de la misma conocidos por la epigrafía ${ }^{4}$ - constituye una importante evidencia de los fuertes vínculos que la fundación de Marcelo mantuvo desde sus comienzos con Roma y, en general, con el mundo itálico. Tal circunstancia es ciertamente común a otros núcleos de población hispanos de similar antigüedad y relevancia, si bien en el caso de Córdoba, por el estatus jurídico y la condición de capital de una de las principales provincias del Occidente romano que logró alcanzar, cobra todavía mayor relieve. 
Los avances de la investigación arqueológica acaecidos en los últimos años han puesto de manifiesto la realidad material de tal vinculación, detectada para la época republicana fundamentalmente a través de los modelos constructivos desarrollados en la arquitectura doméstica ${ }^{5}$, y en la de carácter público ${ }^{6}$, al igual, claro está, que en la propia planificación de la ciudad ${ }^{7}$. No obstante, esta clara dependencia en cuanto a los modelos $o$, si se prefiere, esta implantación de las formas artísticas típicamente romanas e itálicas en Córdoba quedará bien patente, sobre todo, a partir de la época imperial (para la cual, en verdad, contamos con más datos), no sólo en los ámbitos o aspectos que acabamos de citar $^{8}$, sino también en otros como el de la arquitectura funeraria ${ }^{9}$ o el de la plástica tanto de ambiente público como privado. Es precisamente en el interesante campo de la ornamentación escultórica de Colonia Patricia en el que nos vamos a centrar en estas breves páginas, efectuando un rápido recorrido por algunas de las obras de este tipo más destacadas halladas hasta la fecha en Córdoba. La estrecha conexión que la decoración escultórica mantuvo siempre con los espacios y edificios de la ciudad en los que se ubicó aconseja realizar esta apretada síntesis en función de los principales sectores de la misma actualmente conocidos.

\section{El área del foro colonial}

Nuestro itinerario se inicia con los comentarios sobre tres piezas procedentes del área del foro colonial, auténtico centro neurálgico de la ciudad desde la época republicana hasta mediados del siglo IV d.C. situado entre las actuales calles Cruz Conde y Góngora ${ }^{10}$. En primer lugar, sobresalen dos estatuas fragmentadas y acéfalas cuya vinculación con el fenómeno del culto imperial está, creemos, fuera de toda duda. Nos estamos refiriendo a una representación masculina semidesnuda del tipo «Júpiter sedente» (Lám. 1) y a la pieza que debió hacer pendant con ella, una figura femenina también sedente aunque vestida con chiton e himation (Lám. 2). Ambas fueron halladas hacia 1983 en el solar número 4 de la calle San Álvaro ${ }^{11}$. La cronología claudia de estas esculturas, determinada principalmente por razones de estilo, y su tipología (un emperador representado como Júpiter en su trono y un personaje femenino asimismo entronizado y tal vez asimilado a Ceres o Juno), permiten plantear con suficientes garantías la posibilidad de que dichas estatuas representaran a divo Augusto y a diva Augusta (es decir, Livia tras su divinización), respectivamente ${ }^{12}$. De este modo, 
La implantación de las formas artísticas romanas...

LÁmina 1: Torso masculino sedente de la C/ San Álvaro, 4.

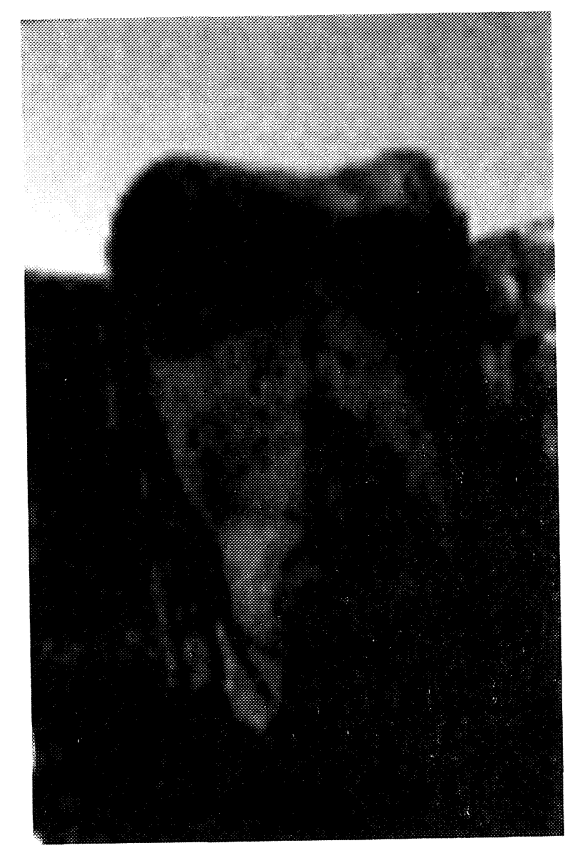

LÁmina 2: Torso femenino sedente de la C/ San Álvaro, 4.

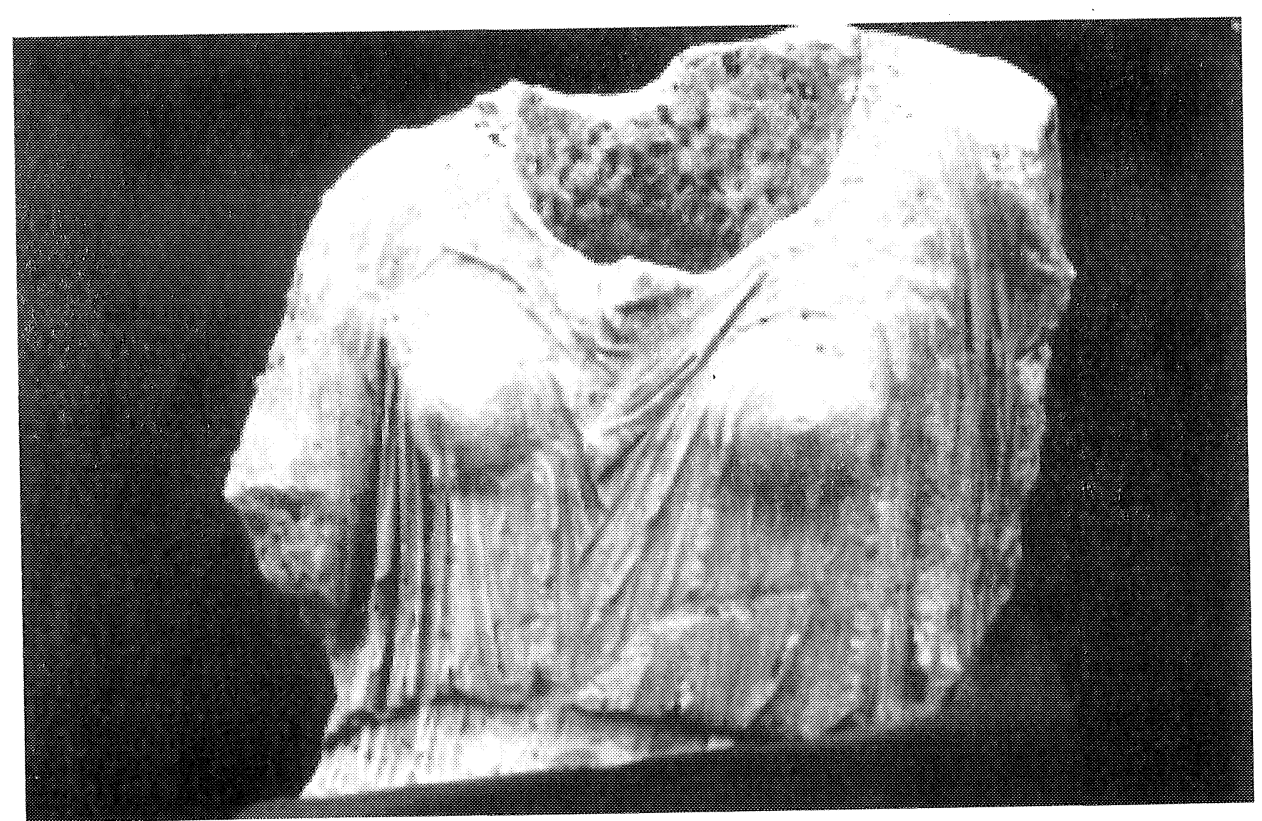


las dos esculturas cordobesas se convierten en un referente obligado para la reconstrucción de las efigies de estos mismos personajes erigidas, por idénticas fechas, en el interior del templo dedicado a ambos en Roma, efigies hoy perdidas pero conocidas a través de representaciones numismáticas ${ }^{13}$. Este hecho pone claramente de manifiesto la fidelidad de la Colonia Patricia a los modelos utilizados en Roma que, aun cuando en el caso de los tipos comentados remiten a plena época clásica, no obstante conocieron un importante desarrollo durante el principado augusteo y, sobre todo, bajo el gobierno de los emperadores julioclaudios, constituyéndose en elementos iconográficos fundamentales de la propaganda dinástica.

Es bastante probable que las dos estatuas de la calle San Álvaro hubiesen salido de un mismo taller, pues poseen rasgos estilísticos comunes, observables tanto en el tratamiento de las zonas lisas como de las plegadas, y parecen haber sido trabajadas en un tipo similar de mármol. Sin embargo, en el estado actual de nuestros conocimientos resulta sumamente difícil discernir si dicho taller fue local o foráneo.

Del entorno del foro colonial ${ }^{14}$ procede también un interesante fragmento de relieve que muestra uno de los actos públicos más importantes para la sociedad romana: la ofrenda y el sacrificio a los dioses. La parte conservada corresponde a la representación mutilada de un $\mathrm{ca}$ millus, esto es, un joven asistente del sacerdote principal, que porta una bandeja con frutos en su brazo derecho, mientras que en la mano izquierda debía agarrar el jarro ritual o urceus, realizado en una pieza aparte, probablemente metálica, como atestiguan los orificios efectuados en la superficie del mármol para su inserción (Lám. 3) ${ }^{15}$. Podemos suponer que el resto de la escena contó con los personajes habitualmente presentes en este tipo de celebraciones religiosas, es decir, el sacerdote que dirigía el acto, los victimarii, encargados de transportar al animal que se pretendía sacrificar junto al altar y de proceder a su inmolación, y los músicos, tal y como evidencian las diversas representaciones de las mismas que han llegado hasta nosotros, entre las cuales sobresalen la placa correspondiente al sacrificio de Eneas en el Ara Pacis de Roma ${ }^{16}$, el altar del templo del Genius Augusti en Pompeya ${ }^{17}$, o el relieve del sacrificio de Agripa hallado en Mérida ${ }^{18}$. Sin embargo, a diferencia de estos conocidos paralelos, la pieza cordobesa -fechada muy posiblemente en época julioclaudia a tenor de los rasgos estilísticos que presenta- muestra delante del camillus restos de lo que parece ser una sella curulis, lo cual induce a pensar en la presencia en este relieve del emperador. Teniendo en cuenta el tema representado, la calidad de la labra y el lugar de procedencia del fragmento, podría 
La implantación de las formas artísticas romanas...

LÁMINA 3: Relieve con escena de ofrenda procedente de la C/ Góngora

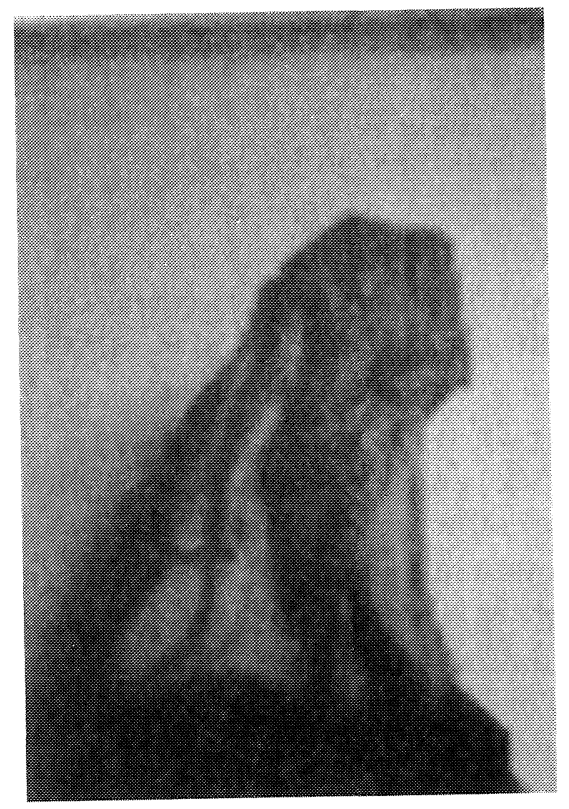

proponerse la pertenencia de éste a un monumento cordobés de carácter religioso y singular relevancia ubicado en el foro colonial ${ }^{19}$.

\section{El forum adiectum o forum novum}

A las más recientes investigaciones de C. Márquez debemos la identificación de un amplio espacio monumental de carácter público situado justo al sur del foro de la colonia, en el entorno de la actual calle Morería, que ha sido designado con los nombres de forum adiectum o forum novum para distinguirlo precisamente de aquél ${ }^{20}$. Esta gran plaza estuvo presidida por un templo de dimensiones colosales, emparentado en cuanto a su modelo y a la ejecución de sus partes con los aurea templa de Roma ${ }^{21}$, cuya cimentación ha sido localizada en un solar de la citada calle Morería en el transcurso de una intervención arqueológica de urgencia ${ }^{22}$. También debió contar este foro con pórticos que albergarían su correspondiente ornamentación escultórica. Además de los pequeños fragmentos hallados a principios de siglo en esta zona de la ciudad, depositados en el Museo Arqueológico de Córdoba y pendientes en buena parte de estudio, el principal testimonio conservado 
de dicha ornamentación está constituido hoy día por la estatua loricata de tamaño colosal de la colección Tienda (Lám. 4).

Considerada en un primer momento como una posible imagen victoriosa de Trajano o Adriano ${ }^{23}$ y posteriormente como una estatua del dios Marte ${ }^{24}$ o de Augusto ${ }^{25}$, en la actualidad la hipótesis interpretativa más probable es la que sostiene que, en realidad, esta magnífica obra de clara inspiración helenística constituyó una representación del héroe troyano Eneas en compañía de su padre Anquises y de su hijo Ascanio-Iulo, o bien de Rómulo con los spolia opima ${ }^{26}$. Ello significa que en este imponente foro cordobés, al igual que sucedió en el «foro de mármol» de Mérida ${ }^{27}$ o en el foro provincial de Tarragona ${ }^{28}$, se emuló (en los casos de Córdoba y Mérida podemos suponer que bastante fielmente) la decoración escultórica del Foro de Augusto en Roma ${ }^{29}$, lo cual no hace sino subrayar la estrecha relación de dependencia que las capitales provinciales hispanas mantenían con la Urbs.

Por lo que respecta a la cronología de la pieza, ésta no ha estado exenta de cierta polémica. Así, descartada hoy día su adscripción a las etapas adrianea o flavia planteada por A. García y Bellido ${ }^{30}$ y C.C. Vermeule ${ }^{31}$, repectivamente, y pese a derivar, como acabamos de señalar, de un innegable modelo augusteo, se ha propuesto para

LÁmina 4: Estatua loricata colosal de la colección Tienda.

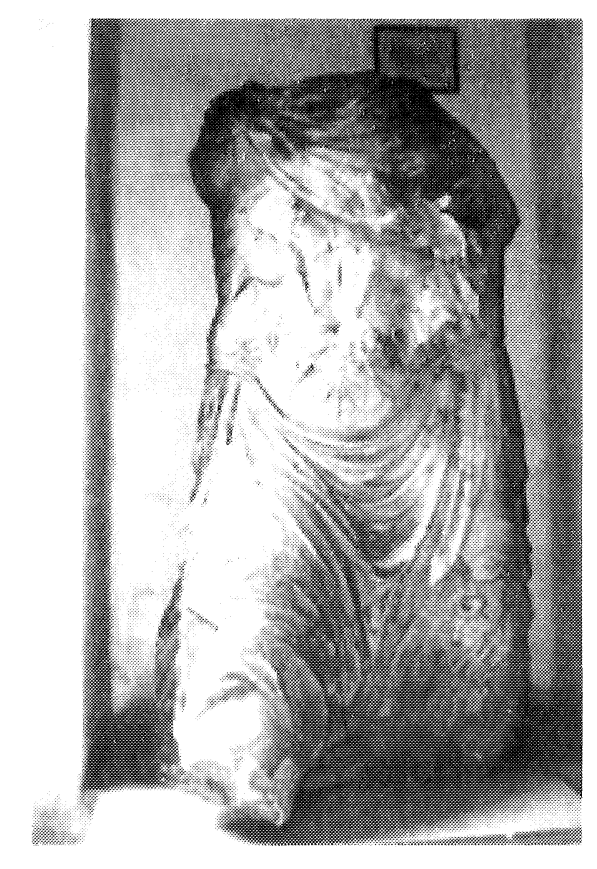


La implantación de las formas artísticas romanas...

ella una datación en época del emperador Claudio ${ }^{32}$. No obstante, últimamente se ha sugerido una cronología julioclaudia temprana en función del tratamiento del mármol - especialmente en la zona de la coraza-, que resultaría plenamente acorde, por lo demás, con la del inicio de la construcción del forum adiectum o forum novum ${ }^{33}$. En cualquier caso, la estatua colosal de la colección Tienda viene a demostrar la adhesión incondicional de las élites cordobesas al regimen imperial implantado por Augusto y remite, dada su excepcional calidad, a la intervención directa de un taller romano o, al menos, itálico.

Por otro lado, aun cuando no podemos afirmarlo con seguridad, es bastante probable que los once togados fragmentados de época claudio-neroniana hallados en los años 70 en un solar de la actual Ronda de los Tejares ${ }^{34}$ formasen parte en su día de la ornamentación escultórica de este foro, a modo de galería de summi viri, de la misma forma que las representaciones de los personajes ilustres de la historia real y mitológica de Roma exornaban el Foro de Augusto en la capital del Imperio. Dichos togados, quizás los de mejor factura de toda Hispania, fueron trabajados por un taller foráneo en mármol de Carrara y son, asimismo, pese a su estado fragmentario, una notable ejemplo del importante papel que las representaciones togadas romanas tuvieron en el terreno de la plástica.

\section{El «foro de Altos de Santa Ana»}

Un nutrido y heterogéneo grupo de testimonios escultóricos cordobeses procede de la actual calle Ángel de Saavedra y de su entorno inmediato. Muchas de esas piezas, que han llegado a nosotros por lo general bastante fragmentadas o deterioradas, aún se encuentran prácticamente inéditas, necesitadas por tanto de un estudio detallado que esperamos sea realizado en un futuro próximo ${ }^{35}$. No obstante, otras han sido publicadas en diversas ocasiones y han contribuido enormemente a la interpretación de esta zona como un espacio público y monumental estrechamente relacionado, desde sus propios inicios, con el culto y la propaganda imperiales ${ }^{36}$. Dicho espacio pudo estar presidido por un gran edificio religioso dedicado a Diana ${ }^{37}$-y, posiblemente, también a Apolo ${ }^{38}$ - cuya decoración arquitectónica habría imitado, al menos en lo que a las basas se refiere, a la del templo de Apolo in Circo de Roma ${ }^{39}$.

Entre las esculturas recuperadas en la calle Ángel de Saavedra se hallan las cabezas-retratos de la emperatriz Livia, esposa de Augusto (Lám. 5) ${ }^{40}$, y de su hijo, el emperador Tiberio (Lám. 6) ${ }^{41}$. Ambas son 


\section{José Antonio Garriguet Mata}

164

LÁmina 5: Cabeza-retrato de Livia de la C/ Ángel de Saavedra

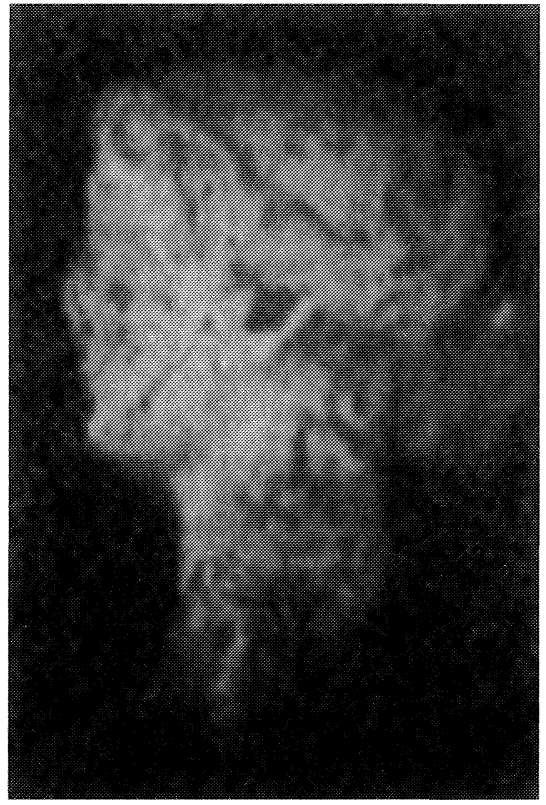

LÁmina 6: Cabeza-retrato de Tiberio de la C/ Ángel de Saavedra, 5

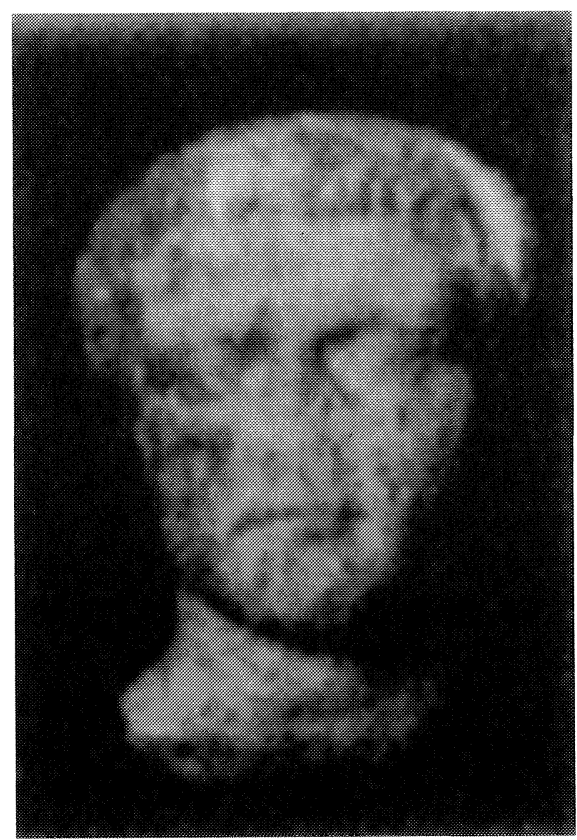


obras salidas posiblemente de un taller local que, sin embargo, reflejan bien los modelos de representación oficial de dichos personajes emanados desde Roma a comienzos de época tiberiana. Podrían ser coetáneos, por consiguiente, de la petición que una embajada de la Bética realizó a Tiberio de erigir en dicha provincia un templo dedicado a él y a su madre ${ }^{42}$. Ahora bien, no quiere esto decir que los retratos mencionados pertenezcan a sendas imágenes de culto de Livia y Tiberio, pues por un lado sabemos que este último denegó el permiso para levantar el templo aludido y, por otro, la cronología de las esculturas podría ser algo anterior a la fecha en la que se envió la consabida embajada (el año 25 d.C.). Pero sí creemos que tanto los retratos cordobeses de Livia y Tiberio como el texto de Tácito pueden entenderse, de algún modo, como un claro reflejo de la lealtad que la ciudad de Córdoba quiso demostrar en las primeras décadas del siglo I d.C. hacia los principales miembros de la familia imperial julioclaudia, en especial a Livia.

Otra pieza destacada procedente de la calle Ángel de Saavedra y vinculada igualmente a la esfera del arte oficial es un pequeño fragmento perteneciente a una estatua masculina del tipo Hüftmantel ${ }^{43}$, creación de época helenística que conoció un amplio desarrollo en Roma y en sus provincias entre mediados del siglo I a.C. y el tercer cuarto del siglo I d.C., muy especialmente - a partir del principado augusteopara la representación de emperadores heroizados o divinizados ${ }^{44}$. La manera en la que ha sido trabajado el mármol en la zona del abdomen y en los pliegues del manto de la pieza cordobesa (Lám. 7) sugiere también una cronología tiberiana temprana, por lo que cabe pensar que tal vez nos encontremos ante los restos de una estatua de Divus Augustus que, como debió suceder con los mencionados retratos de Livia y Tiberio, habría formado parte de una galería de la familia imperial julioclaudia similar a las que se han documentado en muchas otras ciudades romanas ${ }^{45}$. En dicho ciclo escultórico quizás se habrían integrado también dos estatuas femeninas vestidas, casi completas, estudiadas con detalle recientemente ${ }^{46}$. Cabe la posibilidad, avalada por algunos ejemplos hispanos bien conocidos ${ }^{47}$ pero no constatada por el momento en el caso que nos ocupa, de que este grupo estatuario imperial hubiese contado, además, con efigies de Germánico y de Druso el Menor, dos personajes de especial relevancia política durante los primeros años del gobierno de Tiberio ${ }^{48}$. Por otro lado, la presencia de Augusto en este espacio de Colonia Patricia queda asimismo patente, aunque en este caso de manera indirecta, a través del hallazgo en la calle Ángel de Saavedra de una esfinge egipcia, probable alusión a la victoria del princeps sobre Egipto tras la batalla de Actium ${ }^{49}$. 


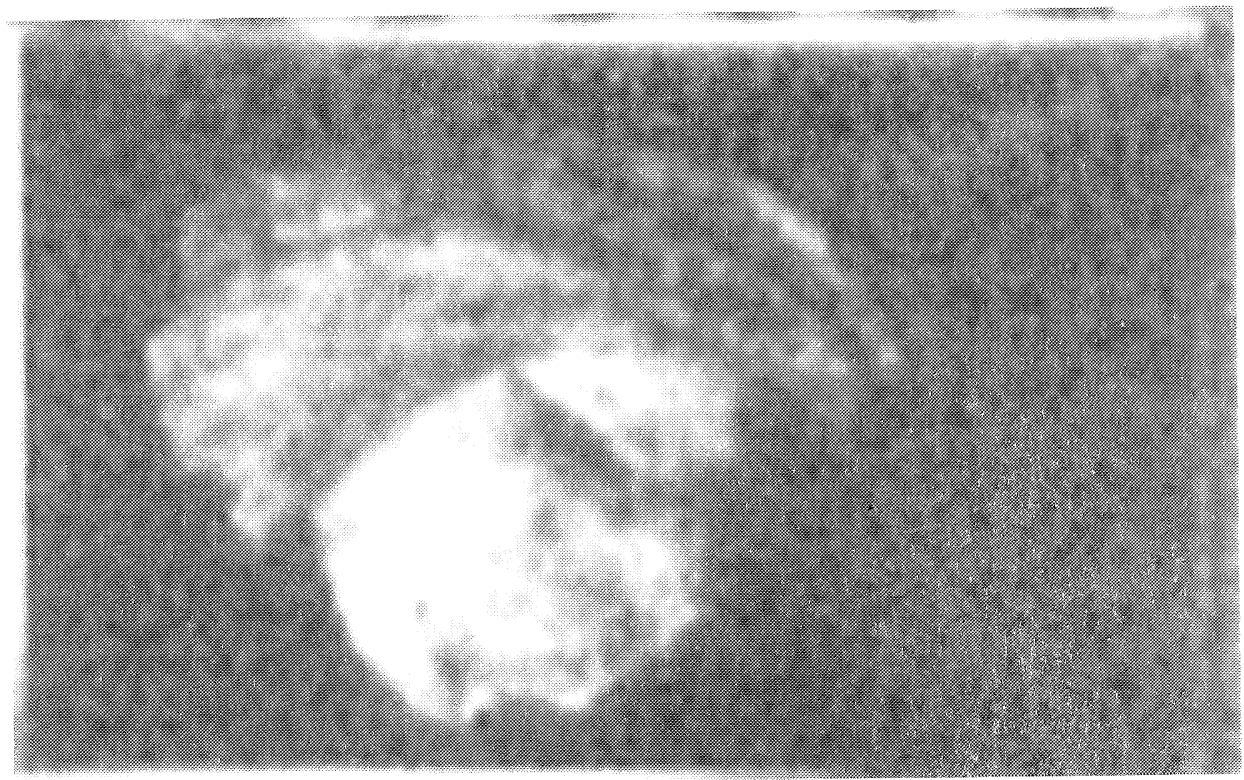

Aunque procede supuestamente de este mismo entorno, el hermaretrato del Museo Arqueológico de Córdoba que representa a un personaje masculino joven e imberbe cuya cabeza aparece ceñida con una diadema (Lám. 8) no parece que formara parte de la ornamentación escultórica oficial del denominado "foro de Altos de Santa Ana». Antes bien, cabría considerarla mejor como una escultura de ámbito doméstico, en cuyo caso puede suponerse que habría formado parte de la ornamentación escultórica de una rica domus cordobesa próxima al citado foro y perteneciente a una familia de elevado estatus social y cultural. Identificado en un primer momento como el retrato juvenil de un príncipe helenístico por A.M ${ }^{\mathrm{a}}$ Vicent ${ }^{50}$, la pieza ha sido estudiada posteriormente en mayor profundidad por $\mathrm{M}^{\mathrm{a}} \mathrm{L}$. Loza, quien se ha decantado, sin embargo, por la representación de un atleta o de Hércules ${ }^{51}$. Esta segunda interpretación parece ser la más acertada a tenor de los paralelos ofrecidos por Loza, a los que puede sumarse un herma muy similar al de Córdoba conservado en el Museo Gregoriano Profano ex Lateranense ${ }^{52}$. 
La implantación de las formas artísticas romanas...

LÁmINA 8: Herma-retrato de Hércules procedente de la C/ Ángel de Saavedra

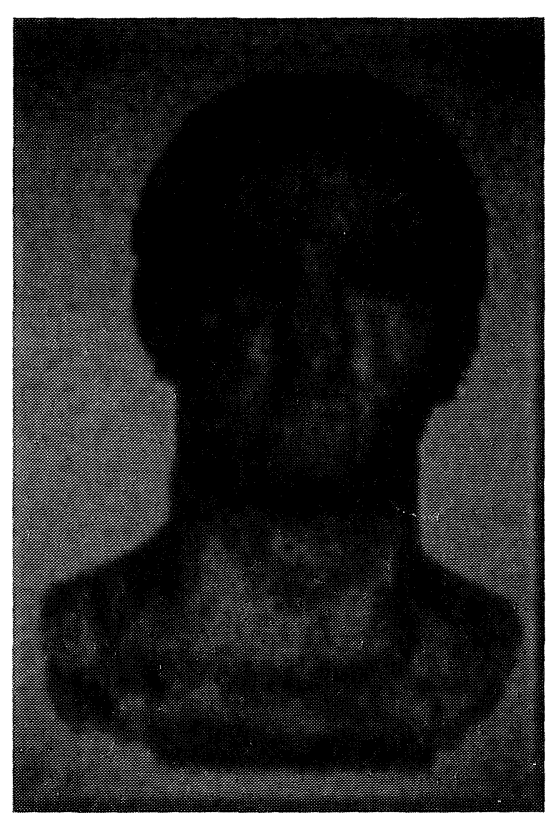

\section{El teatro}

Los trabajos de investigación desarrollados desde 1994 por el Seminario de Arqueología de la Universidad de Córdoba y, más concretamente por A. Ventura y C. Márquez, en el solar del Museo Arqueológico han dado como resultado el descubrimiento en dicho solar del teatro romano de la ciudad ${ }^{53}$. Junto a una serie de plazas escalonadas $y$, presumiblemente, al anfiteatro, este edificio quedó emplazado en un sector de Colonia Patricia que ha sido denominado a raíz de su funcionalidad lúdica como «barrio de espectáculos» ${ }^{54}$. Gracias a los trabajos comentados, hoy se sabe tambien que el teatro romano de Córdoba, el de mayores dimensiones no sólo de toda Hispania sino también de las provincias occidentales, siguió el modelo del teatro de Marcelo en Roma y que su construcción, iniciada en época augustea, corrió a cargo de potentados locales y, muy posiblemente, del emperador o de algún miembro de la familia imperial ${ }^{55}$.

La ornamentación escultórica relacionada con este edificio que se conoce hasta la fecha es bastante escasa, si bien cabe esperar el hallazgo de nuevas piezas en un futuro cercano ${ }^{56}$. Destacan una máscara teatral femenina descubierta junto a la Mezquita-Catedral que adornaría, a 
manera de clave de arco, una de las puertas de entrada al recinto ${ }^{57}$; dos estatuas-fuentes de ninfas con veneras de producción local localizadas en las proximidades de la plaza de Jerónimo Páez y fechadas en el siglo II d.C. ${ }^{58}$; y un retrato muy erosionado del emperador Antonino Pío (Lám. 9) hallado en uno de los patios del Museo ${ }^{59}$. Todas estas obras responden perfectamente a los programas ornamentales típicos de los teatros romanos bien conocidos a través de ejemplos hispanos y extrapeninsulares.

LÁmina 9: Cabeza-retrato de Antonino Pío hallada en uno de los patios del Museo

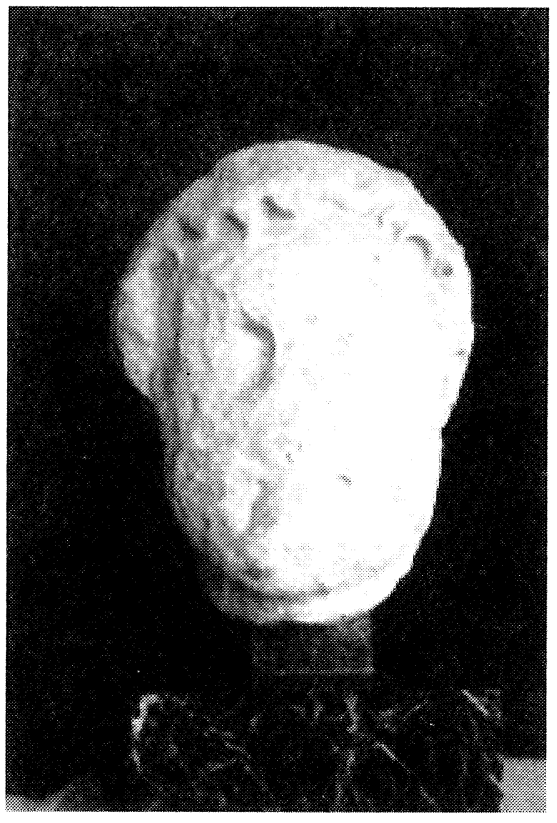

\section{El complejo religioso de la calle Claudio Marcelo}

Excavado y parcialmente reconstruido desde finales de los años 1950, el templo de culto imperial de la calle Claudio Marcelo ha sido objeto en las dos últimas décadas de diversos estudios dirigidos por J.L. Jiménez que han permitido aquilatar tanto su cronología fundacional, la época claudio-neroniana, como la de su pérdida de funcionalidad y desmantelamiento, hechos acaecidos entre finales del siglo III y principios del siglo IV d.C. ${ }^{60}$. Este templo, cuyo principal paralelo es la Maison Carrée de Nîmes, se hallaba aproximadamente en el centro de una plaza con pórticos en tres de sus lados que medía unos 
80 × $60 \mathrm{~m}$. Su decoración arquitectónica remite a viejos modelos augusteos y fue elaborada al parecer por un «buen taller local» ${ }^{61}$. En fechas muy recientes, las excavaciones efectuadas por la Gerencia de Urbanismo del Ayuntamiento de Córdoba en el Palacio de Orive y en la denominada «manzana de San Pablo» han sacado a la luz el circo de la ciudad altoimperial, que habría mantenido una estrecha relación con el recinto religioso presidido por el templo de la calle Claudio Marcelo ${ }^{62}$. Este esquema templo-circo, documentado en Ankyra (Asia Menor) y en Tarragona, encuentra su modelo en el complejo del Palatino de Roma ${ }^{63}$, lo cual permite recalcar una vez más a la estrecha vinculación de Colonia Patricia con la Urbs.

Con respecto a la decoración escultórica asociada a este espacio monumental de carácter religioso, sólo se tiene noticia del hallazgo en esta zona de unos cuantos fragmentos marmóreos de reducido tamaño pertenecientes a estatuas masculinas y femeninas vestidas, así como de un pie de bronce y de los restos de una estatua ecuestre del mismo material descubierta en la calle María Cristina ${ }^{64}$, y de un fragmento colosal de mármol localizado en un muro del siglo IV d.C. que tal vez correspondiese a la estatua de culto del templo ${ }^{65}$. Se trata, por tanto, de una documentación todavía bastante exigua que apenas si constituye un pálido reflejo de lo que debió ser uno de los programas ornamentales más importantes de la ciudad.

Además de todas estas esculturas procedentes de los principales espacios y edificios públicos de la Córdoba altoimperial, existen muchos otros testimonios escultóricos de singular relevancia cuyo lugar de hallazgo resulta imposible conocer en la mayoría de los casos. Entre los de más reciente descubrimiento se encuentra una copia de la Afrodita agachada - creación del escultor helenístico Doidalsas de Bitinia- hallada en 1993 en un solar de la calle Amparo, cerca del río Guadalquivir y del ángulo SE de la muralla que ceñía a Colonia Patricia ${ }^{66}$. Esta obra, única por el momento en lo que hace referencia a la escultura de la Península Ibérica aunque con numerosos paralelos (la mayoría de los cuales procedentes de Roma), pudo formar parte de la decoración de unas termas públicas. Ha sido fechada en época de los antoninos en atención a su estilo ${ }^{67}$, si bien no cabe descartar del todo otras posibilidades cronológicas. También en el terreno de la plástica ideal merecen destacarse por su notable calidad y por tener su origen en prototipos griegos del siglo IV a.C. dos cabezas, una masculina y otra femenina, conservadas en sendas colecciones particulares cordobesas. La primera ha sido interpretada como imagen de una divinidad juvenil realizada en época tardoadrianea ${ }^{68}$, mientras que la segunda corres- 
pondería a una representación de Ártemis-Diana fechada durante el periodo julioclaudio ${ }^{69}$.

Finalmente, entre la escultura de ámbito privado sobresalen un importante conjunto de hermae decorativos conservados en el Museo Arqueológico cordobés que está siendo estudiado en profundidad por A. Peña ${ }^{70}$ y un pequeño grupo escultórico de temática erótica constituido por un sileno y una panisca. Dicho grupo, de procedencia desconocida aunque muy posiblemente cordobesa, se conserva en la colección de la familia Romero de Torres y ha sido fechado en torno al tercer cuarto del siglo I d.C. ${ }^{71}$. Es este campo de la ornamentación escultórica de ambiente doméstico uno de los que habrán de someterse próximamente a un análisis concienzudo a partir de los fondos del Museo Arqueológico de Córdoba y de las colecciones privadas, junto a otros como el de la plástica de carácter funerario, cuyo estudio, iniciado en fechas recientes por I. López ${ }^{72}$, esperamos se vea pronto complementado ${ }^{73}$.

En definitiva, la imagen que de la Córdoba romana está surgiendo a partir de las intervenciones arqueológicas desarrolladas en los últimos años y de la revisión minuciosa de los hallazgos acaecidos con anterioridad - labor a veces poco ensalzada pero tan meritoria y válida, a nuestro juicio, como la excavación de un nuevo solar- es la de una importante y típica ciudad del Occidente del Imperio que se miró constantemente en Roma, reflejando en sus manifestaciones artísticas de cada momento ${ }^{74}$ la mentalidad y el gusto netamente romanos de sus habitantes.

\section{Notas}

1 Este tema ha sido debatido y analizado en numerosas publicaciones. Para un estado de la cuestión reciente, vid. A.U. Stylow, "De Corduba a Colonia Patricia. La fundación de la Corduba romana", P. León (ed.), Colonia Patricia Corduba: una reflexión arqueológica, Sevilla, 1996, 77 ss.

2 Strab. III, 2, 1.

3 J.R. Carrillo et alii, "Córdoba. De los orígenes a la Antigüedad Tardía", Córdoba en la Historia. La construcción de la Urbe, Córdoba, 1998, 26 ss.

4 Se trata del vicus forensis $\left(C I L \mathrm{II}^{2} / 7,272\right)$ y del vicus hispanus (CIL $\left.\mathrm{II}^{2} / 7,273\right)$, citados en sendos pedestales de estatuas dedicadas al mismo personaje, el cuestor L. Axio Nasón.

5 J.R. Carrillo, «Evolución de la arquitectura doméstica en Colonia Patricia Corduba", Córdoba en la Historia. La construcción de la Urbe, Córdoba, 1998, 61 ss.

6 C. Márquez, La decoración arquitectónica de Colonia Patricia. Una aproximación a la arquitectura y urbanismo de la Córdoba romana, Córdoba, 1998, 179 ss. y 201 ss. 


\section{La implantación de las formas artísticas romanas...}

7 Dotada casi desde el principio de un imponente recinto amurallado y de una importante red viaria: A. Ventura, El abastecimiento de agua a la Córdoba romana, Córdoba, 1996, 136 ss.; J.R. Carrillo et alii, art. cit (nota 3), 26 ss.; P. León, «Itinerario de monumentalización y cambio de imagen en Colonia Patricia (Córdoba)", AEspA 72, 1999, 39 ss.

8 C. Márquez, op. cit. (nota 6), 203 ss.

9 D. Vaquerizo, «El mundo funerario», D. Vaquerizo (ed.), Córdoba en tiempos de Séneca, Córdoba, 1996, 174 ss; C. Márquez, op. cit. (nota 6), 194 ss.; P. León, art. cit. (nota 7), 50 ss.

10 De este foro se conocen, fundamentalmente, su pavimentación augustea y sus límites en época altoimperial. No obstante, el análisis de los elementos de decoración arquitectónica recuperados en su entorno comienza a arrojar interesantes resultados con respecto a los monumentos que rodeaban y/o daban acceso a la plaza: C. Márquez, op. cit. (nota 6), 174 ss; J.R. Carrillo, et alii, art. cit. (nota 3), 29 y 38 ss.

11 J.A. Garriguet, «Un posible edificio de culto imperial en la esquina sureste del foro colonial de Córdoba", Antiquitas 8, 1997, 73 ss.; id., La imagen del poder imperial en Hispania: tipos estatuarios, Murcia, e.p.

12 Ibid.

13 La estatuas de Divo Augusto y Diva Augusta aparecen representadas en el interior de su templo de Roma en unas monedas acuñadas por Antonino Pío que conmemoran, precisamente, la restitución de dicho templo: H. Hänlein-Schäfer, Veneratio Augusti. Eine Studie zu den Tempeln des ersten römischen Kaisers, Roma, 1985, 86 ss. Asimismo, la presencia de la divina pareja está constatada tanto por los testimonios epigráficos como por la plástica en diversas partes del antiguo Imperio romano -vid. J.A. Garriguet, art. cit. (nota 11)- aunque las estatuas de Córdoba, junto con las de la ciudad itálica de Rusellae, son las que quizás contribuyen mejor a hacernos una idea de cómo fueron las representaciones existentes en el templo de Roma.

14 Concretamente, la pieza se halló en la confluencia de las calles Góngora y Braulio Laportilla, en las proximidades del ángulo NO del foro colonial.

15 J.A. Garriguet, "Relieve con oferente», D. Vaquerizo (ed.), Córdoba en tiempos de Séneca, Córdoba, 1996, 62 ss.

16 E. La Rocca, Ara Pacis Augustae. In occasione del restauro della fronte orientale, Roma, 1986.

17 J.J. Dobbins, «The altar in the sanctuary of the Genius of Augustus in the Forum at Pompeii", RM 99, 1992, 251 ss.

18 W. Trillmich, «Ein historisches Relief in Mérida mit Darstellung des M. Agrippa beim Opfer. Ein Rekonstruktionsversuch", MM 27, 1986, 279 ss.; T. Nogales, "Un altar en el Foro de Augusta Emerita", Actas de la III Reunión de escultura romana en Hispania, e.p.

19 A este respecto, creemos que no debe pasarse por alto el hecho de que en este foro y a principios de época imperial pudo ubicarse un altar de similares características a las del Ara Pacis, como ha propuesto C. Márquez, op. cit. (nota 6), 62 ss. y 174

20 C. Márquez, op. cit. (nota 6); id. "Acerca de la función e inserción urbanística de las plazas en Colonia Patricia», Empúries 51, 1998, 63 ss.

21 C. Márquez, op. cit. (nota 6); id., art. cit (nota 20).

22 Dirigida por I. Carrasco y R. García, a quienes agradecemos sus explicaciones durante nuestra visita. 
23 A. García y Bellido, "Un toracato del "tipo Hierapytna» en Córdoba», AEspA 34,196 ss.

24 C.C. Vermeule, "Hellenistic and roman cuirassed statues", Berytus XV, 1964, 103.

25 P. León, "Ornamentación escultórica y monumentalización en las ciudades de la Bética", W. Trillmich y P. Zanker (eds.), Stadtbild und Ideologie, München, 1990, 373 ss.

26 W. Trillmich, "Los tres foros de Augusta Emerita y el caso de Corduba", P. León (ed.), Colonia Patricia Corduba: una reflexión arqueológica, Sevilla, 1996, 185 ss.

27 W. Trillmich, art. cit. (nota 26), 175 ss.

28 P. Pensabene, "Classi dirigenti, programmi decorativi, culto imperiale: il caso di Tarraco", P. León (ed.), Colonia Patricia Corduba: una reflexión arqueológica, Sevilla, 1996, 197 ss.

29 P. Zanker, Forum Augustum, Tübingen, 1972.

30 A. García y Bellido, art. cit. (nota 23), 196 ss..

31 C.C. Vermeule, art. cit. (nota 24), 103.

32 W. Trillmich, art. cit. (nota 26), 188.

33 P. León, «Itinerario de monumentalización y cambio de imagen en Colonia Patricia (Córdoba)", AEspA 72, 1999, 46.

34 I. López, "El taller de las estatuas togadas de Ronda de Tejares (Córdoba)", $A E s p A$ 71, 1998, 139 ss.

35 Es el caso, por ejemplo, de una cabeza colosal, posiblemente del dios Hermes, o de un fragmento correspondiente a una estatua de Apolo: A. Ventura et alii, "Análisis arqueológico de la Córdoba romana: resultados e hipótesis de la investigación", $P$. León (ed.), Colonia Patricia Corduba: una reflexión arqueológica, Sevilla, 1996, 101; P. León, art. cit. (nota 33), 47; J.A Garriguet, "Reflexiones en torno al denominado "foro de Altos de Santa Ana" y a los inicios del culto dinástico en Colonia Patricia Corduba", AAC 10, 1999, 93 ss.

36 A.U. Stylow, "Apuntes sobre el urbanismo de la Corduba romana", W. Trillmich y P. Zanker (eds.), Stadtbild und Ideologie, München, 1990, 274 ss.; A. Ventura, op. cit. (nota 7), 145 ss.; C. Márquez, op. cit. (nota 6), 179 ss.; I. López, Estatuas masculinas togadas y estatuas femeninas vestidas en colecciones cordobesas, Córdoba, 181 ss.; J.R. Carrillo et alii, art. cit. (nota 3), 39 ss.; P. Léon, art. cit. (nota 33), 46 ss.; J.A. Garriguet, art. cit. (nota 35).

37 A. Ventura, «Resultados del seguimiento arqueológico en el solar de C/ Angel de Saavedra $\mathrm{n}^{\circ}$ 10, Córdoba", $A A C$ 2, 262 ss.; id., op. cit. (nota 7), 146; C. Márquez, op. cit. (nota 6), 181 ss.

38 J.A. Garriguet, art. cit. (nota 35).

39 C. Márquez, op. cit. (nota 6), 182.

40 A.M." Vicent, "Retrato de Iulia Augusta en el Museo Arqueológico Provincial de Córdoba", Homenaje a D. Domingo Fletcher. Archivo de Prehistoria Levantina XVII, 1987, tomo I, 351 ss; id., Retratos romanos femeninos del Museo Arqueológico de Córdoba. Discurso de ingreso en la Real Academia de Ciencias, Bellas Letras y Nobles Artes de Córdoba, Córdoba, 1989, 13 ss.; J.A. Garriguet, «Retrato de la emperatriz Livia», D. Vaquerizo (ed.), Córdoba en tiempos de Séneca, Córdoba, 50 ss.; id., art. cit. (nota 35).

41 A.M. ${ }^{a}$ Vicent, "Lote de esculturas romanas de los Altos de Santa Ana", Corduba Archaeologica 15, 1985, 57; J.A. Garriguet, "Retrato del emperador Tiberio», D. Vaquerizo (ed..), Córdoba en tiempos de Séneca, Córdoba, 52 ss.; id. art. cit. (nota 35). 


\section{La implantación de las formas artísticas romanas...}

42 Tac., Ann. IV, 37.

43 J.A. Garriguet, art. cit. (nota 35).

44 H.G. Niemeyer, Studien zur statuarischen Darstellung der römischen Kaisers, Berlín, 57 ss; S. Maggi, "Augusto e la politica delle immagini: lo Hüftmanteltypus", RdA 14, 1990, 63 ss.

45 C.B. Rose, Dynastic commemoration and imperial portraiture in the Julio-Claudian period, New York.

46 I. López, op. cit. (nota 36), 68 ss. y 76 ss.; id., "Estatuas femeninas procedentes del espacio público de los Altos de Santa Ana en Colonia Patricia (Córdoba)", Habis 30, 1999, 330 ss.

47 Por ejemplo, los de Antequera y Medina Sidonia: vid. A. Blanco, «Retratos de príncipes julio-claudios en la Bética", BRAH CLVI, 1965, 89 ss.; A. García y Bellido, "Los retratos de Livia, Drusus Minor y Germanicus de Medina Sidonia", Mélanges d'Archeologie et d'Histoire offerts à A. Piganiol, I, París, 1966, 481ss.

48 P. León, "Hacia una nueva visión de la Córdoba romana ", P. León (ed.), Colonia Patricia Corduba: una reflexión arqueológica, Sevilla, 1996, 26.

49 A.M Vicent, art. cit. (nota 41), 57 ss.; P. León, art. cit. (nota 33), 46 ss.; J.A. Garriguet, art. cit. (nota 35).

50 A.M. ${ }^{a}$ Vicent, art. cit. (nota 41), 58 ss.

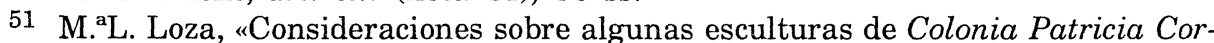
duba ", P. León (ed.), Colonia Patricia Corduba: una reflexión arqueológica, Sevilla, 1996, 264 ss.

52 C. Vorster, Museo Gregoriano Profano ex Lateranense. Katalog der Skulpturen. Römische Skulpturen des späten Hellenismus und der Kaiserzeit 1, Mainz am Rhein, 1993, 140 ss.

53 A. Ventura, El abastecimiento de agua a la Córdoba romana, Córdoba, 1996, 151 ss.; C. Márquez, La decoración arquitectónica de Colonia Patricia. Una aproximación a la arquitectura y urbanismo de la Córdoba romana, Córdoba, 1998, 182 ss.

54 A. Ventura, op. cit. (nota 53), 176; J.R. Carrillo et alii, «Córdoba. De los orígenes a la Antigüedad Tardía", Córdoba en la Historia. La construcción de la Urbe, Córdoba, 1998, 32 ss.

55 A. Ventura, op. cit. (nota 53), 151 ss; C. Márquez, op. cit. (nota 53), 182 ss.; J.R. Carrillo et alii, art. cit. (nota 54), 34 ss; P. León, art. cit. (nota 33), 47 ss..

56 Actualmente se están llevando a cabo nuevas excavaciones en el interior del Museo Arqueológico, dirigidas por A. Ventura, que completan a las efectuadas en años anteriores y que permitirán reconstruir en buena medida el aspecto externo del teatro gracias a la conservación de muchas de sus piezas.

57 A. Ventura, "Relieve de máscara teatral», D. Vaquerizo (ed.), Córdoba en tiempos de Séneca, Córdoba, 1996, 90 ss.; C. Márquez, op. cit. (nota 53), 189 ss.

58 M.L. Loza, "Estatuas-fuentes romanas de Colonia Patricia Corduba», AAC 4, 1993, 143 ss; A. Ventura, op. cit. (nota 53), 106 ss.

59 M. Wegner, «Römische Herrscherbildnisse des zweiten Jahrhunderts in Spanien», $A E s p A$ 26, 1953, 77; J.A. Garriguet, «Retrato de Antonino Pío procedente del teatro romano de Córdoba", Antiquitas 9, 1998, 79 ss.

60 J.L. Jiménez, «El templo romano de la calle Claudio Marcelo en Córdoba: aspectos cronológicos, urbanísticos y funcionales», $P$. León (ed.), Colonia Patricia Corduba: una reflexión arqueológica, Sevilla, 1996, 129 ss; J.L. Jiménez y M M. Ruiz, "Resultados de la excavación arqueológica en el solar de la calle María Cristina en 
Córdoba, situado a espaldas del templo romano", $A A C$ 5, 1994, 119 ss.; J.L. Jiménez, $\mathrm{M}^{\mathrm{a} D}$. Ruiz y M. Moreno, "Nuevos avances en el conocimiento sobre el urbanismo de Colonia Patricia Corduba en el sector ocupado por el templo romano", AAC 7, 1996, 115 ss.

61 P. León, art. cit. (nota 33), 48.

62 J.R. Carrillo et alii, (nota 54), 40 ss..

63 Ibid., 41.

64 I. López, op. cit. (nota 36), 182 ss..

65 J.L. Jiménez, "Notas sobre un fragmento escultórico procedente del recinto presidido por el templo romano de la calle Claudio Marcelo en Córdoba", Actas de la II Reunión sobre escultura romana en Hispania, Tarragona, 1996, 49 ss.

66 L. Aparicio, "Una réplica de "Afrodita agachada" en Córdoba", $A A C$ 5, 1994, 181 ss.; A. Ventura, op. cit. (nota 53), 113 ss.

67 L. Aparicio, art. cit. (nota 66), 184 ss.

68 J. Beltrán, «Notas sobre la escultura ideal de la Bética», Actas de la II Reunión sobre Escultura romana en Hispania, Tarragona, 1996, 62 ss.

69 P. León, «Ornamentación escultórica y monumentalización en las ciudades de la Bética", W. Trillmich y P. Zanker (eds.), Stadtbild und Ideologie, München, 1990, 377 ss.; M ${ }^{\mathrm{a}} \mathrm{L}$. Loza, art. cit. (nota 51), 265 ss.

70 A. Peña, Hermas decorativos del Museo Arqueológico de Córdoba, Memoria de Licenciatura en elaboración, Universidad de Córdoba.

71 C. Márquez, "Artes decorativas en la Córdoba romana», $A A C$ 8, 1997, 77 ss.

72 I. López, «Estatuas togadas funerarias de Colonia Patricia (Córdoba)», AAC 8, 1997, 95 ss.; id., op. cit. (nota 36), 183 ss.

73 En este sentido, el proyecto de investigación Espacio y usos funerarios en Colonia Patricia Corduba, que actualmente dirige el Prof. Dr. Desiderio Vaquerizo constituye un marco idóneo para lograr este cometido. Dicho Proyecto ha sido concedido y financiado por la Digicyt con apoyo de Fondos FEDER.

74 Aunque en este trabajo nos hemos referido a un número muy reducido de piezas fechadas en los siglos I y II d.C, no puede olvidarse que la Corduba bajoimperial, pese a las transformaciones sufridas en su fisonomía, siguió siendo un importante núcleo de población que mantuvo puesta su mirada en Roma y en las corrientes artísticas que a ella llegaban, como evidencian, por ejemplo, los diferentes sarcófagos hallados en la ciudad: vid. J. Beltrán, Los sarcófagos romanos de la Bética con decoración de tema pagano, Málaga, 1999, 93 ss. 